\title{
Retraction Note: A new prediction method for surface settlement of deep foundation pit in pelagic division based on Elman-Markov model
}

\author{
Yubao Zhan ${ }^{1}$. Jun Zhang ${ }^{1}$. Qihua Liu' · Pengqiang Zheng ${ }^{1}$ \\ Published online: 13 December 2021 \\ (c) Saudi Society for Geosciences 2021
}

Retraction Note: Arabian Journal of Geosciences (2021) 14: 1345

https://doi.org/10.1007/s12517-021-07603-4

The Editor-in-Chief and the Publisher have retracted this article because the content of this article is nonsensical. The peer review process was not carried out in accordance with the Publisher's peer review policy. Author Yubao Zhan disagrees with the retraction. Authors Jun Zhang, Qihua Liu and Pengqiang Zheng have not responded to correspondence regarding this retraction.

The original article can be found online at https://doi.org/10.1007/ s12517-021-07603-4.

Yubao Zhan

zhanyubao0030@163.com

1 College of Resources, Shandong University of Science and Technology, Tai' an 271019, China 